\title{
Psychophysical similarities between rats and humans
}

\author{
HANNES EISLER \\ University of Stockholm, Stockholm, Sweden
}

\begin{abstract}
Church and Deluty (1977) found that rats bisected pairs of durations at their geometric mean and concluded that the psychophysical function for duration in rats is logarithmic. From the same experimental finding and the assumption that the similarity between the short duration and the bisection point equals the similarity between the bisection point and the long duration, together with the unidimensional similarity function proposed by Eisler and Ekman (1959), Stevens' psychophysical power function is derived instead. Since the similarity function thus seems to hold for animals as well as for humans, dealing with similarities appears to make more perceptual than cognitive demands.
\end{abstract}

Church and Deluty (1977) trained rats to respond with one of two levers when presented with a short duration and with another lever when presented with a long one for a number of pairs of durations. After completion of the training, the rats were also presented, for each pair, durations between the short and the long one. The duration at which the rats distributed their responses equally between the two levers was considered the point of bisection of the particular temporal intervals. The main objective of Church and Deluty's experiment was to distinguish between several psychophysical functions for duration in rats. From the finding that the point of bisection approximately agreed with the geometric mean of the short and the long durations, they concluded that the psychophysical function is logarithmic.

A logarithmic function for duration in rats is at variance with some findings using direct scaling methods (Catania, 1970; Platt, Kuch, \& Bitgood, 1973), according to which subjective time in rats grows as a power function, as well as with later findings of Church (Note 1). The aim of the present study is to show that Church and Deluty's (1977) results are compatible with a power function as well.

Let us introduce three psychophysical functions with physical time as domain and subjective time as range: $f$ for the short ("Lever $A$ ") duration, $g$ for the long ("Lever B") duration, and $h$ for the duration corresponding to the bisection point. Let I be an open interval that contains the whole experimental range, and assume that $\mathrm{f}(\mathrm{d}) \leqslant \mathrm{h}(\mathrm{d}) \leqslant \mathrm{g}(\mathrm{d})$ for each $\mathrm{d}$ in I. Assume further that $f(d), g(d)$, and $h(d)$ are

This work was supported by the Swedish Council for Research in the Humanities and Social Sciences. I am indebted to Olivier Guilbaud for mathematical assistance. Requests for reprints should be sent to Hannes Eisler, Department of Psychology, University of Stockholm, Box 6706, S-11385 Stockholm, Sweden. positive, nondecreasing, differentiable, and not identically constant functions of $d$ in $I$.

Let the two time intervals of a pair be $\mathrm{x}$ and $\mathrm{y} \mathrm{sec}$, $\mathrm{x}<\mathrm{y}$, and the bisection point $\mathrm{z}$ sec. According to Church and Deluty (1977), the bisection point $z$ is the geometric mean of $x$ and $y$ :

$$
\mathrm{z}=(\mathrm{xy})^{1 / 2} \text {. }
$$

According to Church and Deluty (1977), the duration corresponding to the point of bisection is characterized by

$$
\mathrm{S}(\mathrm{x}, \mathrm{z})=\mathrm{S}(\mathrm{z}, \mathrm{y}),
$$

where $\mathrm{S}$ denotes similarity. Equation 2 implies that the similarity between the short duration and the duration corresponding to the bisection point equals the similarity between the bisection point and the long duration.

The unidimensional similarity function is

$$
\mathrm{s}_{\mathrm{ij}}=\frac{2 \min \left(\Psi_{\mathrm{i}}, \Psi_{\mathrm{j}}\right)}{\Psi_{\mathrm{i}}+\Psi_{\mathrm{j}}}
$$

(Eisler, 1960; Eisler \& Ekman, 1959; Ekman, Goude, \& Waern, 1961), where $s_{\mathrm{ij}}$ denotes the similarity between stimuli $i$ and $j$, and $\Psi_{i}$ is the subjective magnitude of $i$. The similarity function will be commented on later.

From what was said above follows the relation

$$
\frac{2 f(x)}{f(x)+h(z)}=\frac{2 h(z)}{h(z)+g(y)}
$$

Rearranging yields

$$
[h(z)]^{2}=f(x) \cdot g(y) .
$$


Thus, also for subjective duration, the bisection point is the geometric mean. Inserting Equation 1 into Equation 5 yields

$$
\left\{\mathrm{h}\left[(\mathrm{xy})^{1 / 2}\right]\right\}^{2}=\mathrm{f}(\mathrm{x}) \cdot \mathrm{g}(\mathrm{y}) .
$$

We now show, under the additional assumption that Equation 6 holds for any $\mathrm{x}<\mathrm{y}$ in I, that $\mathrm{f}, \mathrm{g}$, and $h$ must be power functions in $I$. The solution of the functional Equation 6 is obtained by taking the derivatives with respect to $\mathrm{x}$ and $\mathrm{y}$ :

$$
2 h\left[(x y)^{1 / 2}\right] \cdot h^{\prime}\left[(x y)^{1 / 2}\right] \cdot \frac{y^{1 / 2}}{2 x^{1 / 2}}=f^{\prime}(x) \cdot g(y),
$$

and

$$
2 h\left[(x y)^{1 / 2}\right] \cdot h^{\prime}\left[(x y)^{1 / 2}\right] \cdot \frac{x^{1 / 2}}{2 y^{1 / 2}}=f(x) \cdot g^{\prime}(y)
$$

Equations 7 and 8 yield

$$
\frac{x^{1 / 2}}{y^{1 / 2}} f^{\prime}(x) \cdot g(y)=\frac{y^{1 / 2}}{x^{1 / 2}} f(x) \cdot g^{\prime}(y),
$$

which can be rearranged to

$$
\frac{y \cdot g^{\prime}(y)}{g(y)}=\frac{x \cdot f^{\prime}(x)}{f(x)}
$$

Since the left member of Equation 10 is a function of $y$ only, and the right of $x$ only, each member must equal the same constant for any $\mathrm{x}, \mathrm{y}$ in $\mathrm{I}$. We obtain the differential equation

$$
\frac{x \cdot f^{\prime}(x)}{f(x)}=\beta, x \in I,
$$

where the constant $\beta$ must be positive, since $f^{\prime}(x)>0$ for at least one $x$ in $I$ (recall that $f$ is assumed to be nondecreasing and not identically constant in I). Equation 11 is equivalent to

$$
\frac{d}{d x}[\ln f(x)-\beta \ln x]=0, \quad x \in I,
$$

which implies

$$
\ln f(x)-\beta \ln x=\ln \alpha_{f}, \quad x \in I ;
$$

that is,

$$
f(x)=\alpha_{f} x^{\beta}, \quad x \in I .
$$

The constant $\alpha_{\mathrm{f}}$ must be positive, since $\mathrm{f}$ is assumed to be positive in I. Obviously, the same solution is obtained for the left member of Equation 10, except for the multiplicative constant $\alpha_{\mathrm{g}}: \mathrm{g}(\mathrm{y})=\alpha_{\mathrm{g}} \mathrm{y}^{\beta}, \mathrm{y} \in \mathrm{I}$. From the assumption that $\mathrm{f}(\mathrm{d}) \leqslant \mathrm{g}(\mathrm{d})$ for each $\mathrm{d}$ in $\mathrm{I}$, it follows that $\alpha_{\mathrm{f}}$ and $\alpha_{\mathrm{g}}$ must satisfy $\alpha_{\mathrm{f}} \leqslant \alpha_{\mathrm{g}}$. Inserting these solutions for $\mathrm{f}(\mathrm{x})$ and $\mathrm{g}(\mathrm{y})$ into Equation 6 yields $h(z)=\alpha_{h} z^{\beta}, z \in I$, where

$$
\alpha_{\mathrm{h}}=\left(\alpha_{\mathrm{f}} \cdot \alpha_{\mathrm{g}}\right)^{1 / 2} .
$$

Thus Stevens' psychophysical power function holds throughout, although the scale units $\alpha$ may or may not be the same. (It is easy to show just by insertion that a power function satisfies Equation 6, but to prove the uniqueness of the solution, the derivation above was carried out.) Note that since the exponent $\beta$ of the power function cannot be determined from Church and Deluty's (1977) experiment, the course of the psychophysical function remains unknown. It might as well be accelerating as decelerating like a $\log$ function, or linear.

However, we should not forget that the derivation of Equation 14 is based on the ideal case (cf. Eisler \& Montgomery, 1974). The experimentally obtained bisection points deviate somewhat from the geometric means. These discrepancies can probably be handled, in addition to letting the scale vary differently from Equation 15, by introducing a subjective zero $\Phi_{0}$ in the power function:

$$
\Psi=\alpha\left(\Phi-\Phi_{0}\right)^{\beta},
$$

where $\Phi$ denotes physical and $\Psi$ subjective magnitude. The parameter $\Phi_{0}$ has been shown to be of importance particularly for studies of subjective time (in humans, cf. Eisler, 1975).

The similarity function, Equation 3, has found some support recently. It is a special case of the "ratio model" for similarity proposed by Tversky (1977), and it has been internally validated by Fagot (1979). Fagot introduced a correction factor for bias; however, this factor cancels out in going from Equation 4 to Equation 5 .

It should perhaps be pointed out that replacing Equation 3 for similarity with the simple assumption that similarity equals the ratio of the smaller over the larger subjective magnitude (cf. Sjöberg, 1971) likewise leads to Equation 5 (and thus to Equation 14).

A third way of arriving at Equation 5 is based on the implicit assumption of Church and Deluty (1977) that the difference (distance) is the same between the point of bisection and each of the two outer points of each pair of durations. If we assume that this relation holds for a transformed subjective magnitude and that the transformation is logarithmic (cf. Eisler, 1978), we see that

$$
\ln [\mathrm{h}(\mathrm{z})]-\ln [\mathrm{f}(\mathrm{x})]=\ln [\mathrm{g}(\mathrm{y})]-\ln [\mathrm{h}(\mathrm{z})]
$$


entails Equation 5. But if in Equation 17 one replaces $\mathrm{f}(\mathrm{x})$ by $\mathrm{x}$, and so on, as Church and Deluty did implicitly, one sees that also the log function entails Equation 1. The log function can also be derived uniquely in the same way as the power function above, starting with Equation 17 and replacing $\ln [\mathrm{f}(\mathrm{x})]$ by $\mathrm{u}(\mathrm{x})$, and so on.

The observant reader may have noticed that, after the second paragraph, there is no further mention of the rats. From this and the outcome of the derivation, it can be concluded that at least some psychophysical laws hold for rats and for humans. The finding that the psychophysical power function is valid for both animals and humans is neither surprising nor new. Of more interest, perhaps, is that the similarity function, Equation 3, seems also to be valid for rats. Not being willing to endow rats with the same cognitive capacities as man, we may conclude that dealing with similarities taps more of a perceptual than of a cognitive ability, perhaps in a manner like Landahl's (1945) neurobiophysical mechanism for similarity.

\section{REFERENCE NOTE}

1. Church, R. M. Personal communication, November 1978.

\section{REFERENCES}

Catania, A. C. Reinforcement schedules and psychophysical judgments. In W. N. Schoenfeld (Ed.), The theory of reinforce- ment schedules. New York: Appleton-Century-Crofts, 1970.

Сhurch, R. M., \& Deluty, M. Z. Bisection of temporal intervals. Journal of Experimental Psychology: Animal Behavior Processes, 1977, 3, 216-228.

EISLE R, H. Similarity in the continuum of heaviness with some methodological and theoretical considerations. Scandinavian Journal of Psychology, 1960, 1, 69-81.

Eisle R, H. Subjective duration and psychophysics. Psychological Review, 1975, 82, 429-450.

Eisle R, H. On the ability to estimate differences: A note on Birnbaum's subtractive model. Perception \& Psychophysics, 1978, 24, 185-189.

Eisler, H., \& Eкman, G. A mechanism of subjective similarity. Acta Psychologica, 1959, 16, 1-10.

Eisler, H., \& Montgomery, H. On theoretical and realizable ideal conditions in psychophysics: Magnitude and category scales and their relation. Perception \& Psychophysics, 1974, 16, 157-168.

Ekman, G., Goude, G., \& Waern, Y. Subjective similarity in two perceptual continua. Journal of Experimental Psychology, $1961,61,222-227$.

FAGOT, R. F. Nested models of relative judgment: Applications to a similarity averaging model. Perception \& Psychophysics, 1979, 26, 255-264.

LANDAhL, H. D. Neural mechanisms for the concepts of difference and similarity. Bulletin of Mathematical Biophysics, $1945,7,83-88$.

Platt, J. R., Kuch, D. O., \& Bitgood, S. C. Rats' lever-press durations as psychophysical judgments of time. Journal of the Experimental Analysis of Behavior, 1973, 19, 239-250.

SjöвERG, L. Three models for the analysis of subjective ratios. Scandinavian Journal of Psychology, 1971, 12, 217-240.

Tversky, A. Features of similarity. Psychological Review, 1977, 84, 327-352.

(Received for publication May 17, 1980.) 